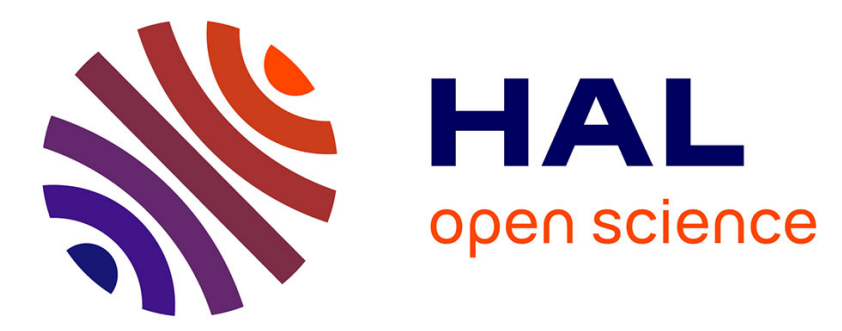

\title{
Similar Concepts, Distinct Solutions, Common Problems: Learning from PLM and BIM Deployment
} J. R. Jupp, Vishal Singh

\section{To cite this version:}

J. R. Jupp, Vishal Singh. Similar Concepts, Distinct Solutions, Common Problems: Learning from PLM and BIM Deployment. 11th IFIP International Conference on Product Lifecycle Management (PLM), Jul 2014, Yokohama, Japan. pp.31-40, 10.1007/978-3-662-45937-9_4 . hal-01386473

\section{HAL Id: hal-01386473 \\ https://hal.inria.fr/hal-01386473}

Submitted on 24 Oct 2016

HAL is a multi-disciplinary open access archive for the deposit and dissemination of scientific research documents, whether they are published or not. The documents may come from teaching and research institutions in France or abroad, or from public or private research centers.
L'archive ouverte pluridisciplinaire HAL, est destinée au dépôt et à la diffusion de documents scientifiques de niveau recherche, publiés ou non, émanant des établissements d'enseignement et de recherche français ou étrangers, des laboratoires publics ou privés. 


\title{
Similar Concepts, Distinct Solutions, Common Problems: Learning from PLM and BIM Deployment
}

\author{
Jupp JR ${ }^{1}$ and Singh $\mathrm{V}^{2}$ \\ ${ }^{1}$ University of Technology, Sydney; ${ }^{2}$ Aalto Univeristy \\ Julie.Jupp@uts.edu.au; Vishal.Singh@aalto.fi
}

\begin{abstract}
This paper describes the similarities and differences between Product Lifecycle Management and Building Information Modelling concepts, focusing on integration issues relative to their methods, information systems, effects and criticisms. In this literature based discussion, the authors show that the two concepts share fundamental similarities but are distinct in their scope and level of integration as well as maturity of process and workflow management. The paper highlights several common problems and aims to provide guidance for deployment initiatives.
\end{abstract}

Keywords: Building information modelling, product lifecycle management, business processes, information systems, information technologies.

\section{Introduction}

A variety of lifecycle management concepts enabled by advances in business process integration and information technology (IT) have been developed in various sectors. In manufacturing sectors, Product Lifecycle Management (PLM) has evolved to provide platforms for the creation, organization, and dissemination of product-related knowledge across the extended enterprise [1]. In the construction sector, a renewed focus on lifecycle processes is emerging within the BIM (building information modelling) paradigm, an object oriented approach to creating, managing and using construction project data. Whilst both are relatively new concepts, PLM stands as a more established approach, seeing steady uptake since the mid-1990s. BIM has only recently become the accepted term for the production and management of a built asset's information throughout design, construction and operations [2].

Recently comparisons have begun to relate PLM and BIM concepts, contrasting the functionalities and capabilities of their methods and systems, see [3, 4, 5]. These studies are beginning to examine their similarities and differences; however a number of open questions remain relative not only to their concepts, methods, and systems but also their intended effects and criticisms. In reviewing the literature, the authors present a comparative analysis that explores these questions to provide a broader account of PLM and BIM relative to the unique structural characteristics of each sector. The remainder of the paper is divided into four sections. Sections 2 and 3 review PLM and BIM concepts, information systems, effects and criticisms. Section 4 compares and discusses their main attributes and shared problems, before closing the paper with a discussion and summary of research contribution. 


\section{Product Lifecycle Management}

Stark [6] broadly describes PLM as simply the activity of managing products effectively across their lifecycle. Understanding the evolution of PLM is helpful to expounding Stark's definition. Emerging from product data management (PDM), which provides data management capabilities [7, 8] PLM extends beyond the engineering aspects of a product to provide a shared platform for the creation, organization, and dissemination of all product-related knowledge across the extended enterprise [1]. PLM is thus a strategic business approach to the collaborative creation, management and exchange of product lifecycle information [9].

\subsection{Concept and Methods}

The general idea behind PLM is to serve up-to-date data, information and knowledge in a secure way to all people who are part of the product lifecycle [10]. Information is produced by a variety of participants at different levels of detail in diverse functions inside and outside a firm [11]. Complexity increases when moving from data towards knowledge, with data and information easier to store, describe, and manipulate [1]. The range of data, information and knowledge across an extended enterprise must be integrated correctly throughout the lifecycle. Various methods, systems and engineering tools are required to organize, store, access, convert and exchange these different forms correctly and seamlessly. Consequently generating appropriate data, information, and knowledge structures is critical [8]. IT infrastructure is therefore central to PLM, including hardware, software, and Internet technologies, and underlying representation and computing languages. In manufacturing industries, the product lifecycle is typically divided into three distinct phases: beginning/middle/end of life (BOL/MOL/EOL). PLM transverses these phases and assists a corporation and its extended enterprise in meeting functional- and data- level requirements [12]. Together numerous methods, systems and engineering tools form the systems architecture of a PLM solution. Currently, these are mostly deployed in the BOL phase to support design and development. However the application of IT in MOL and EOL phases is increasing as customer needs and technologies mature [10].

PLM functionality is achieved via 'system components', including the IT Infrastructure as well as a Product Information Modelling Architecture (PIMA), a Development Toolkit, and a set of Business Applications [11]. PIMA includes product ontology and interoperability standards. A development toolkit provides the means for building Business Applications and extends PLM functions to include kernels (e.g. geometry), visualization tools, data exchange standards and mechanisms, and databases. Business applications provide PLM functionalities to process corporate intellectual capital [11]. There are different types of functional- and data- level requirements of PLM system architectures. According to Jun [12], the functional-level requirements of PLM are defined by the large amounts of structured and unstructured data that are created, updated, transferred, removed, reused and stored in several application systems across the extended enterprise. The requirements for handling this include: real-time data acquisition, closed-loop information flow, interoperability between devices and application systems, integration with existing systems and services and the 
collaborative environment [12]. Data-level requirements relate to product and productrelated data (e.g., business, maintenance and expiration data). For seamless interface between product and product-related data requirements surround the use of standardized data, data interoperability, product information traceability, data encryption, and user authentication [12].

\subsection{Information Systems and Technologies}

Depending on the level of integration, implementation and system architecture, the deployed information systems may include: Systems engineering (SE), Product design, Product and portfolio management (PPM), Engineering data management (EDM), Manufacturing process management (MPM), PDM, Enterprise resource planning (ERP) and and supply chain management (SCM). To limit the scope of this discussion, our review utilizes Crnkovic's PLM integration taxonomy [13] to rationalize the information systems utilized. Crnkovic defines three levels of integration: full, loose and no integration.

Full integration: a package with all functions using common structures, data, user interfaces and application programming interfaces (APIs). The integration model has a layered architecture. The lowest tier is the data repository layer, which includes databases, file systems and information models [13]. The middle tier is the business layer, with tools and services to support business logic. The uppermost tier is the user interface layer. All layers are connected to each other using standardized APIs. A single database for all the data is superior in terms of data quality, because loss of data in exchange between systems is reduced and duplication is low [13].

Loose integration: the different information systems operate more independently and store data in their own repositories. The information models in the repositories are different and can only be accessed from native tools. Information exchange between tools is carried out by additional interoperability functions. The advantage is that it does not require a common information model and enables the use of tools from different vendors. Disadvantages stem from the lack of a common information model, requiring interoperability functions, through middleware mechanisms acting as a 'middle layer' in PLM integration. Data inconsistencies pose a risk.

No integration: all data transfers are done manually, increasing the risk of data inconsistencies, human error, and the lack of standardization in information models. The data update routines such as import and export functions need to be well defined.

\subsection{Effects}

As companies use PLM in different ways, the extent of its effects is contingent on the field of business and level of integration. The business case for PLM is usually linked to the reduction of operational level information systems and an increase in operational excellence [10]. Manufacturers can speed up the realization of complex products. Product engineers can shorten implementation and engineering change approval cycles across the extended design team. Purchasing agents can work more effectively with suppliers to reuse parts. Executives get a high-level view of all important information, 
from details of the manufacturing line to parts failure rates culled from warranty data and field information [14]. The effects of PLM may also include staff reduction, data integration, standardization, access to timely and complete information, improving customer service, creative and collaborative work methods; customization of products based on complex customer desires, lead-time reduction, prototype cost reduction, and reduction in late product changes [10].

PLM centres on the BOM (bill of materials), with methods, processes and legacy tools needing to be modular, follow standards and be reusable [11]. PLM integration must be flexible to react to changes in the market, organization structure, business processes, product and tools. Consequently data, processes and software should ideally be aggregated to reduce system complexity [15] and the use of open data standards is crucial. Numerous standards have emerged for the horizontal and vertical integration of PLM systems. MIMOSA and ISO are two leading bodies that develop such standards employed in PLM [31]. Examples include the STEP-Standard for the exchange of product model data (ISO 10303), covering data exchange through life. There are ongoing efforts to make STEP universally available using XML and UML standards. MIMOSA's OSA-EAI (OSA for Enterprise Application Integration) and OSA-CBM (Open System Architecture for Condition Based Maintenance) are also established and utilised [16].

\subsection{Criticisms}

There are several unique challenges related to business process and technological integration relative to the PLM concept, as documented in several case studies, see e.g., [10, 14, 15]. Many criticisms of PLM can be traced to: (a) failings in PLM technology; (b) 'elusive standard engineering processes' as the foundation for PLM; (c) organizational issues; and (d) dynamic environments.

Failings of PLM Technology: PLM solutions lack maturity; this is mostly due to high levels of technical complexity and incomplete data standards. Whilst PLM's functional footprint is improving, it is common to require multiple proprietary solutions to address each company's needs spanning the development lifecycle. PLM solutions are typically a complex collection of tools that are often loosely connected [15]. Depending on the overall architecture, the functionalities of systems and tools used might overlap causing redundancies, rework and data quality deterioration. Also, data standards and corporation-wide integration architectures are ongoing development activities and are not fully established [10, 15].

Elusive Standard Engineering Process: Whilst the development process may be viewed as standard across product groups and businesses, once details of how a company actually develops a product (how decisions are made, who is involved at various stages, how partner collaborations are executed, etc.), the nuances of a company's product development practices become visible [15]. The practices of seemingly similar product development and engineering processes can differ wildly across companies and between products developed in the same company.

Organizational Issues: Due to the diversity of engineering tools and subsystems there is a tendency to delegate PLM deployment to engineering executives, who traditionally manage technology rollouts [15]. This approach works for choosing point 
solutions, e.g., CAD tools, but studies show that it does not work well for enterprisewide integration platforms $[14,15]$. The main criticism being that different business functions generate and deal with product data in disparate ways. Related criticisms include: improper executive management expectations, frustrated end-users, high implementation costs, and evasive returns on investment [15].

Dynamic Environments: The systems and practices that underlie lifecycle management are continuing to undergo significant changes. New and emerging IT, rapid globalization of businesses, and evolving core functions such as collaborative design and outsourced manufacturing force companies to continually re-examine their product development practices, which can be costly and time consuming $[6,10]$.

\section{Building Information Modeling}

BIM is an object oriented approach to creating, managing and using various geometric and non-geometric data in a construction project. While conceptually BIM can be used across all the phases of a project lifecycle, starting from design to the demolition of the built environment, in practice, the level of integration and maturity of BIM usage across different phases is contingent on multiple factors defined relative to products (both the design artefact and tools), processes (e.g. operational, methodological, business, legal) and people (e.g. organizations, stakeholders, culture).

\subsection{Concept and Methods}

The evolution of BIM can be traced to simultaneous developments across CAD and information systems; both facilitated by progress in computing power, the emergence personal computers and the internet. The development of the BIM concept and methodology can be explained on the basis of four attributes: 1) representation, 2) information management, 3) inbuilt intelligence, analysis and simulation, and 4) workflow management.

Representation is integral to design, and it has driven the development of BIM in at least two ways. Firstly in terms of design cognition; as processing capabilities improved, computational tools moved from 2D drafting to 3D models, making visualization and working with complex geometries possible. This move from symbolism to virtualization initially led to photo-realistic renderings (based on solid geometry) and later to intelligent object-oriented models (replacing solid geometry). Second, at the level of communication and collaboration; representations used across multidisciplinary design teams demand greater specification of easily comprehended and disambiguated information. This requires higher levels of detail and accuracy in the geometric and non-geometric information contained in object-based models.

While representation and visualization is also part of documenting project-related information, it is equally important to be able to record, manage and use all other forms of building-related data, information and knowledge generated across the project lifecycle. Accordingly, document and information management capabilities that were developed in pre-BIM tools (as an independent set of specifications, documents and 
spreadsheets), have merged and evolved with BIM applications as information that is typically embedded, appended or linked to object-based models. Linking between all forms of geometric and non-geometric data is a critical aspect of BIM. Consequently, traditional users of electronic document management systems - such as contractors and project managers - have the expectation that BIM provides similar information management capabilities, with the added advantage of visualization. In construction, this typically takes the form of a BIM model server (see [17] for a discussion). Depending on the level of BIM implementation and maturity these systems may or may not be enabled in the project environment.

The object-oriented premise of BIM enables integration of CAD and information management capabilities. In doing so, it is possible to intelligently link different objects with relationships and constraints, allowing various forms of automated analysis and simulation, ranging from environmental and structural analysis to cost estimating and construction scheduling. Various forms of building compliance 'checks', such as interference and clash detection, are now common. Increasingly, BIM applications are becoming knowledge-based systems with more and more domain knowledge being integrated. Consequently, the number of BIM applications is expanding rapidly, each catering to different discipline-based requirements.

With the complexity, intelligence and number of BIM applications growing, information and workflow management is critical. Given the richness of buildingrelated and project-related information it is desirable to design and plan the project and discipline-specific workflows. Design process optimization is receiving growing attention in recent efforts to model information flow and develop BIM workflow management frameworks, leading to new cloud-based approaches (see e.g., [19]).

\subsection{Information Systems and Technologies}

BIM shares many characteristics with PLM. The platforms supporting BIM resemble Crnkovic's [14] loose or no integration levels. Technologically, some of the key characteristics of BIM are: 1) Open data standards, 2) Centralised and decentralised BIM, 3) Information exchange standards, and 4) Data and information structures.

To achieve interoperability between BIM applications, open file formats such as the Industry Foundation Class (IFC) have been developed. IFC files can be viewed in most applications but modifications have to be undertaken in the native format and converted back to IFC. This process is error prone. Even if most geometric data can be completely exchanged, the intelligence is often lost in the transformation. Another information exchange method is sharing data through middleware or APIs, however this requires that different links are established between each application.

The BIM database can either be centralized or decentralized. In a centralized approach, information from e.g., a central IFC-based model must be exported, modified within a native format and imported back into the central model using IFCs. This 'roundtrip' is often not a viable option due to interoperability issues [20]. Singh et al. [17] highlight the challenges of system and sub-system integration in a centralized BIM-server approach. Due to this complexity, a decentralized, distributed information management approach is increasingly being considered [20]. In a decentralized approach, collaboration can occur at two levels: (1) within a single organisation or 
discipline using similar tools, and (2) across different discipline-specific models shared and combined using IFCs. IFC standardization has adopted a 'use case centred' approach [21]. Different use cases and information exchange requirements are specified in Information Delivery Manuals (IDM). IDMs together with other model management protocols have given rise to a variety of policy documents such as BIM Management, Coordination and Execution Plans [22].

Object-based building models include both non-modifiable internal data structures, and information structures that enable model management. NBIMS (National BIM Society) lists three potential reference standards that can be used to structure model information; IFC, as discussed above, the Construction Specifications Institute (CSI) OmniClassTM, and CSI IFDLibrary [23]. OmniClass provides a standardized basis for classifying information created and used by the North American AEC (Architectural, Engineering and Construction) industry. The IFD initiative, based on ISO standards and driven by buildingSMART, aims to find a way to create and catalogue a data dictionary of building objects and bring disparate sets of data into a common view of the construction project or asset. In addition to reference standards, a variety of metadata is also contained in the BIM model, e.g., information related to object creation and history. A recent development in BIM systems is towards distributed transactional models, e.g. the DRUM concept [20], which aims to create a mechanism to manage linked partial models such that building information can still be distributed.

\subsection{Effects}

Effects of BIM are visible both at micro (project and organization) and macro (industry and national) levels. The potential benefits of BIM are best exploited through collaborative engagement of different stakeholders from early stages of the project. Accordingly, new forms of project delivery practices are emerging such as Integrated Project Delivery (IPD) - an alliance-based relational contracting approach that aims to align the interests, benefits, roles, risks and responsibilities of all project stakeholder [24]; Big Room - a multidisciplinary BIM coordination office [25]; and 'knotworking' - occasional collocated and intense design sessions when distributed design teams physically get together to make rapid progress [26]. Furthermore, with increasing BIM maturity, its role and scope is expanding to different aspects and domains across the building lifecycle and specific topics for BIM, such as BIM for: facilities and operations management, lean construction, prefabrication, and safety.

At a macro level governments across many countries are mandating the use of BIM to facilitate productivity gains in the AEC sector. Among the various challenges in realizing these mandates is training enough BIM skilled and literate personnel.

\subsection{Criticisms}

BIM has received criticism on various issues, especially concerning, (1) data transfer and systems integration, (2) ill-defined terminology, scope and purpose, and (3) unstructured implementation processes. 
Data transfer and system integration: There are gaps in using BIM smoothly between conceptual design to detail design, design model to construction model, asdesigned to as-built data, etc. These interfaces need to be resolved for effective BIM usage. Also, the integration of BIM with advanced structural analyses techniques such as Finite Element Method has remained a challenge. While open standards have progressed significantly over the last two decades, the commercial interests of software vendors have also stunted the pace of development around interoperability.

Terminology, scope and purpose: The term and concept of BIM is unclear for many, with $M$ in BIM being used interchangeably for models (product), modelling (process), and management (process). This needs to be resolved for stakeholders to reach a shared understanding on what they are committing to. Furthermore, the scope and purpose of BIM in a project is rarely defined clearly, leaving uncertainties about aspects such as the level of detail, information flow and modes of exchange of information across stakeholders, data transfer, model ownership and handover.

Unstructured implementation processes: One of the primary challenges to addressing macro level issues is to understand and plan around the key factors that drive and determine how and where BIM efforts are concentrated. For example, in Finland, the earliest BIM developments that were piloted in 1994, focused on later lifecycle management [27]. However, as the pilot project led to greater interest in BIM, direct and immediate benefits were seen by design consultants and contractors. The resulting market forces led to BIM development concentrating on design and construction phases, while work in facilities and later lifecycle management came to a standstill. In recent years this development is seeing a revival, e.g., developments have looked to establish definition of as-built datasets for FM [28], and the introduction of the COBie initiative (Construction Operations Building information exchange) for the exchange of IFCbased FM data [29].

\section{Discussion}

PLM and BIM share some similarities regarding lifecycle management objectives and the nature of their practice-based criticisms, however they differ in critical areas concerning their underlying methods, scope of business, technological and enterprise integration, and their intended effects. This sections attempts to elucidate these similarities and distinctions so that valuable learning opportunities may be identified.

Similarities exist in the key objectives of PLM and BIM, which include functionalities that support and manage the creation, release, change and verification of product-related information. PLM and BIM platforms typically provide for the same core functions: management of design and process documents and models, development and control of BOM records, provision of electronic file repositories, inclusion of document and model metadata, identification of model content for compliance and verification, provision for workflow and process management for change approvals, control of multi-user secured access, and data export controls. However it should also be noted that whilst BIM platforms have designed to cover these areas, their level of IT maturity and process sophistication appears to be behind that of most PLM system architectures. 
Like PLM, BIM aims to integrate people and data processes throughout the design, construction and operation of a product (or built asset). However it has only been in the last five to seven years that an increasing focus on the application of BIM throughout the whole building lifecycle has emerged and the significance of business systems and business process integration been acknowledged. The literature surveyed reveals a growing number of studies that consider a range of building lifecycle management issues, where much of this research has sought to bridge the interface between AEC processes and the activities of facility operations and management. BIM servers are now being developed to provide a large integrated data- and knowledge-base that can be leveraged not only in design and engineering but also in planning and management of component fabrication, construction operations, and facilities maintenance [30]. Thus research efforts to 'close the loop' and develop the BIM concept for business process integration for the whole building lifecycle are increasing. This increasing scope, functionality and value of BIM is a consequence of platform expansion targeting collaborative processes, shared resources and decision-making to support the whole lifecycle [4].

The adoption of a lifecycle perspective in any sector depends on multiple factors. Depending on the size, cost and complexity of an engineered product or built asset the design and production will normally adhere to discrete stages to form a system lifecycle. In construction, IT implementations that span project or life cycle stages are less established than in manufacturing sectors such as aerospace. The speed and breadth of adoption of IT across the extended enterprise is also greater in these sectors. PLM in manufacturing is therefore a more proven lifecycle integration solution. In construction, even despite BIM-enabled IPD approaches, the flow and management of information is still not fully integrated among all stakeholders. In developing and advancing the BIM concept it is therefore imperative to adopt an ecosystem approach to mapping the network of interacting AEC actors, corporate business processes, project processes, activities, methods and technologies.

\section{References}

1. Ameri, F. \& Dutta D. (2005). Product Lifecycle Management: Closing the Knowledge Loops. Computer-Aided Design \& Applications, 2(5), pp.577-590.

2. Venugopal, M., Eastman, C.M., Sacks, R., Teizer, J. (2012). Semantics of model views for information exchanges using the industry foundation class schema, Advanced Engineering Informatics 26(2), 411-428.

3. Ford, G., Bartley, T., Igba, J, Turner, A., \& McMahon, C. (2013). Product Life Cycle Data Management: A Cross-Sectoral Review, in B. Alain, R. Louis, D. Debasish, (eds.) Product Lifecycle Management for Society, FIP Adv in Inf. and Comm. Tech., Vol. 409, pp. 58-67.

4. Aram, S. \& Eastman, C. (2013), Integration of PLM solutions and BIM systems for the AEC industry, Proceedings of 30th International Symposium of Automation and Robotics in Construction and Mining, Montréal, pp. 1046-1055.

5. Jupp, J.R. (2013). Incomplete BIM implementation: Challenges and role of product lifecycle management functions, in B. Alain, R. Louis, D. Debasish, (eds.) Product Lifecycle Management for Society, IFIP Advances in Information and Communication Technology, Springer Berlin Heidelberg. Vol. 409, pp. 630-640. 
6. Stark, J. (2011). Product lifecycle management: 21st century paradigm for product realization, Springer.

7. PLM Interest Group. PLM vs PDM Definition. Retrieved (Feb. 2014): www.plmig.com/welcome/stdpdmdefn.shtml

8. Mostefai, S., Bouras, A. \& Batouche, M. (2005). Data Integration in a PLM Perspective for Mechanical Products. Intl. Arab Journal of Information Technology 2(2), pp. 141-147.

9. CIMdata (2014). All About PLM, Retrieved (Feb. 2014): www.cimdata.com/en/resources/about-plm

10. Terzi, S., Bouras, A., Dutta, D., Garetti, M. \& Kiritsis, D. (2010). Product lifecycle management - from its history to its new role. Intl. J. of PLM, 4(4), pp. 360-389.

11. Sudarsan R., Fenves, S.J., Sriram, R.D., \& Wang, F. (2005). A product information modeling framework for product lifecycle management, Computer-Aided Design, 37, 1399-1411.

12. Lee, B. \& Suh, S. (2009). An architecture for ubiquitous product life cycle support system and its extension to machine tools with product data model. Int'l J. of Adv. Manuf. Tech, 42(5-6), pp. 606-620.

13. Crnkovic, I., Asklund, U. \& Persson Dahlqvist, A. (2003). Implementing and Integrating Product Data Management and Software Configuration Management, Norwood, MA, Artech House Inc.

14. Vainio, V. (2011). Comparative Research of PLM Usage and Architecture, Masters Thesis, Tampere University of Technology.

15. Hewett, A. (2009). Product Lifecycle Management: Critical Issues and Challenges in Implementation, Inf. Tech. and Product Dev., Annals of Inf. Sys., 5(1), pp.81-105.

16. Koronios, A., Nastasie, D., Chanana, V., Haider, A. (2007), Integration Through Standards: An Overview of International Standards For Engineering Asset Management. In: Fourth International Conference on Condition Monitoring, Harrogate, UK.

17. Singh, V., Gu, N. \& Wang, X. (2011). A theoretical framework of a BIM-based multidisciplinary collaboration platform. Automation in Construction, 20, 134-144.

18. Panchal, J. H., Fernández, M. G., Paredis, C. J., Allen, J. K., \& Mistree, F. (2004). Designing design processes in product lifecycle management: Research issues and strategies. In ASME 2004 Int'l Design Eng Tech Conf. pp. 901-913.

19. Rezgui, Y., Beach, T., \& Rana, O. (2013). A governance approach for BIM management across lifecycle and supply chains using mixed-modes of information delivery. J. of Civil Eng. \& Mgmt, 19(2), 239-258.

20. Törmä, S. \& Granholm, L., (2011). Managing building information as a set of interrelated partial models, Espoo: Working paper.

21. BuildingSMART, (2012). MVD Process. Retrieved (Feb. 2014): http://buildingsmart.com/standards/mvd/mvd-process.

22. Holzer, D (2011), BIM's seven deadly sins, Intl. J. of Arch. Comp., 9 (4), 463-480.

23. NIBS (2007), US National BIM Standard: Version 1, Part 1: Overview, Principles and Methodologies, Retrieved (Feb. 2014): www.wbdg.org/bim/nbims.php

24. American Institute of Architects. (2007). Integrated Project Delivery: A Guide. CA Council.

25. Dolan, K.A. (2010). Building A Hospital Out Of Bits And Bricks. FORBES 186(5), 36-38.

26. Engeström, Y. (2005). Knotworking to create collaborative intentionality capital in fluid organizational fields. Advances in Interdisciplinary Studies of Work Teams 11:307-336.

27. Björk, B.C., Löwnertz, K. \& Kiviniemi, A. (1997). ISO DIS 13567: Proposed Intl. Standard for Structuring Layers in Computer Aided Building Design. ITcon Vol. 2, pp.32-55.

28. Teicholz, P. (2013). Owner BIM for FM Guidelines, in Teicholz P (ed) BIM for FM, Wiley.

29. East, W.E., (2007). Construction Operation Building Information Exchange. USACE ERDC.

30. Beetz, J., van Berlo, L., de Laat, R., \& Bonsma, P. (2011), Advances in development and application of an open source model server for building information. Proc. of CIB W078W102, France. 